IZA DP No. 7466

Migration and Young Child Nutrition:

Evidence from Rural China

Ren $\mathrm{Mu}$

Alan de Brauw

June 2013 


\title{
Migration and Young Child Nutrition: Evidence from Rural China
}

\author{
Ren Mu \\ Texas A\&M University \\ and IZA \\ Alan de Brauw \\ International Food Policy Research Institute (IFPRI)
}

\author{
Discussion Paper No. 7466 \\ June 2013
}

IZA

P.O. Box 7240

53072 Bonn

Germany

Phone: +49-228-3894-0

Fax: +49-228-3894-180

E-mail: iza@iza.org

\begin{abstract}
Any opinions expressed here are those of the author(s) and not those of IZA. Research published in this series may include views on policy, but the institute itself takes no institutional policy positions. The IZA research network is committed to the IZA Guiding Principles of Research Integrity.

The Institute for the Study of Labor (IZA) in Bonn is a local and virtual international research center and a place of communication between science, politics and business. IZA is an independent nonprofit organization supported by Deutsche Post Foundation. The center is associated with the University of Bonn and offers a stimulating research environment through its international network, workshops and conferences, data service, project support, research visits and doctoral program. IZA engages in (i) original and internationally competitive research in all fields of labor economics, (ii) development of policy concepts, and (iii) dissemination of research results and concepts to the interested public.
\end{abstract}

IZA Discussion Papers often represent preliminary work and are circulated to encourage discussion. Citation of such a paper should account for its provisional character. A revised version may be available directly from the author. 


\section{ABSTRACT \\ Migration and Young Child Nutrition: Evidence from Rural China*}

The unprecedented large scale rural-to-urban migration in China has left many rural children living apart from their parents. In this study, we examine the impact of parental migration on the nutritional status of young children in rural areas. We use the interaction terms between wage growth in provincial capital cities and initial village migrant networks as instrumental variables to account for migration selection. Our results show that parental migration has no significant impact on the height of children, but it improves their weight. We provide suggestive evidence that the improvement in weight may be achieved through increased access to tap water in migrant households. Concerns about the sustainability of the impact on weight are raised in the conclusions.

JEL Classification: I1, J6, O1

Keywords: migration, children, nutrition, rural China

Corresponding author:

Ren Mu

The Bush School of Government and Public Service

Texas A\&M University

4220 TAMU

College Station, TX 77843

USA

E-mail: rmu@tamu.edu

\footnotetext{
* We are grateful to Nicole Garcia and Feng Huang for great research assistance. For very useful comments, we thank Joyce Chen, Kalena Cortes, Ranjita Misra, Hiroshi Ono, and seminar participants at the 2012 Allied Social Science Associations Annual Conference in Chicago, the Asian Studies Forum in Texas A\&M University, and the 2013 Population Association of America Conference in New Orleans.
} 


\section{Introduction}

The migration of labor out of agriculture is a primary feature of the economic development process, and the study of migration as an economic process has a long history (Lewis, 1954; Fei and Ranis, 1964). The role of migration in the economy has recently regained prominence in policy discussions and in the research community because of an increased flow of labor both internationally and within large countries, such as India and China. However, Clemens (2011) notes that much research has focused on the effects of immigration while neglecting the impacts of emigration on those left behind.

From a microeconomic perspective, the effects of emigration on source households and communities can be complex. Migrants typically continue to have economic interactions with households and communities they leave behind (Stark and Bloom, 1985). These interactions can be particularly important when markets do not function well. For example, migrant remittances can help households overcome credit constraints that hinder investment in the human capital of the next generation (Beine et al., 2008; Yang, 2008). When migrants leave households, however, the time investment in raising children will also decrease (de Brauw and $\mathrm{Mu}, 2011$ ). Moreover, as household members live apart because of migration, they cannot perfectly monitor one another's behavior. Consequently, the adults remaining in the village may not serve the best interests of the children living with them (Chen, 2006). Therefore, migration can affect human capital outcomes of children in several different ways, and the overall effect depends on the relative importance of these factors. 
A focus on children's nutrition is important because poor nutrition outcomes early in life have long term consequences for children (Grantham-McGregor et al., 2007). For example, multiple studies demonstrate that children's health and nutritional status have a sizable and statistically significant positive impact on later educational outcomes in many developing countries, such as Pakistan (Alderman et al., 2001), Ghana (Glewwe and Jacoby, 1995), Guatemala (Maluccio et al., 2009) and Kenya (Miguel and Kremer, 2004). ${ }^{1}$ Benefits are not limited to educational outcomes: longitudinal studies in developing countries also show evidence of improved cognitive measures later in life (Grantham-McGregor et al., 2007). Furthermore, stunting before the age of 5 can lead to less formal employment or lower wages later in life (Walker et al., 2011; Maluccio et al., 2009; Carba, Tan, and Adair, 2009).

Several recent studies suggest that migration can potentially influence nutrition among children left behind by the migrant or migrants. Gibson, McKenzie, and Stillman (2011) find that in Tonga, height-for-age z-scores (HAZ) are lower among children under 18 years old left behind by migrants to New Zealand than among children who accompany migrants. $^{2}$ They find no impact on weight-for-age z-scores (WAZ) or BMIfor-age z-scores (BMIZ). ${ }^{3}$ In Central America, Carletto et al. (2011) and de Brauw (2011) find positive impacts on HAZ scores among Guatemalan and Salvadoran children left behind by emigrants to the United States, respectively. Evidence from Tajikistan also shows that children in communities with more migrants have higher HAZ-scores (Azzarri

\footnotetext{
${ }^{1}$ For a literature review of recent studies on the impact of child health and nutrition on education in less developed countries, please see Glewwe and Miguel (2008).

${ }^{2}$ They also find that children who accompany migrants are healthier using several other measures of health status.

${ }^{3}$ BMI stands for Body Mass Index, calculated by dividing a person's body weight in kilograms by her or his height in meters squared (weight $[\mathrm{kg}] /$ height $[\mathrm{m}]^{2}$ ). BMI z-scores are used like weight-for-height z-scores but also control explicitly for age.
} 
and Zezza, 2011). Mansuri (2006) and Nobles (2007) study the effects of international migration from Pakistan and Mexico, respectively, on child HAZ-scores, with the former finding positive impact but the latter a negative one. Finally, de Brauw and Mu (2011) find that older children (aged 7 to 12 years) are more likely to be underweight, presumably because they spend more time doing household chores than children in nonmigrant households. Younger children (aed 2 to 6 years) are found to be less likely to be overweight when no grandparent lives with them.

One of the major drawbacks to much of the literature linking migration and child nutritional status is that it often lacks an identification strategy. ${ }^{4}$ Many of the papers discussed above are up front about this drawback (e.g. Carletto et. al., 2011; de Brauw, 2011; de Brauw and $\mathrm{Mu}, 2011$ ). Furthermore, previous papers tend to use cross-sectional data, effectively comparing children of migrants with children of non-migrants, rather than tracking children over time.

In this paper, we build upon our previous analysis (de Brauw and Mu, 2011), making several new contributions to the literature. First, we build a panel of observations from the China Health and Nutrition Survey (CHNS) data set of children who are under 5 years old in initial rounds, to be able to control for individual fixed effects. In addition to individual fixed effects, we explicitly attempt to control for the endogeneity of migration by constructing instrumental variables for changes in parental migration status. The instrumental variables used here are the interaction terms of wage growth in provincial capital cities with initial village migrant networks. Initial village migrant networks are absorbed into the individual fixed effects, and we argue that the variation in networks

\footnotetext{
${ }^{4}$ Gibson et al. (2011) use a lottery to credibly identify Tonga-New Zealand migration.
} 
interacted with wage growth at the potential destination will only affect children's nutritional status through migration.

Second, this paper contributes to the small literature on the impacts of migration on child health and nutrition in China. To our knowledge, only Chen (2006) and de Brauw and $\mathrm{Mu}$ (2011) have examined the impacts of migration or off-farm work on children's health or nutritional status in China. ${ }^{5}$ This paper examines average anthropometric variables rather than measuring the nutritional status in the tails of one specific distribution. Moreover, this paper focuses on young children as the literature described above demonstrates that nutritional status is particularly important among younger children.

Our results show that parental migration has no significant impact on young children's HAZ-scores, but it improves their WAZ-scores. We provide suggestive evidence that the improvement in short-term nutrition status may be achieved through increased access to tap water among households with migrants.

The paper proceeds as follows. Section 2 provides more background on China's rural-to-urban migration and the nutritional status of children in rural areas. The third section presents a conceptual framework, and the fourth section discusses the data we use and the empirical framework for the paper. The econometric results are presented and discussed in the fifth section. The final section concludes.

\section{Background on Migration and Child Nutrition in China}

\footnotetext{
${ }^{5}$ Chen (2006) uses earlier rounds of the CHNS to show that child health among older children is not affected by father absence in the past month. She also finds that caloric intakes increase when fathers are away.
} 
China is a particularly salient place to study the implications of migration for children in source communities for several reasons. First, the flow of internal migrant labor has increased rapidly since economic reforms began and in particular since labor market restrictions were loosened (Liang and Ma, 2004; Fan, 2008). However, migrants are still largely barred, either legally or financially, from accessing education for their children in urban areas partially due to the household registration (hukou) system,. Poor housing conditions for migrant workers in urban areas also prevent family migration (World Bank, 2009). Consequently, whole-family migration is rare, and many young and school-age children stay behind in rural villages. Therefore many children of migrants remain in rural areas. Recent estimates suggest that as many as 23 million children (under age 14) are left behind in migrant-sending regions while their parents are working elsewhere (Guo, 2009).

\subsection{Increasing Migration and Children Left Behind in Rural China}

China's labor market experienced dramatic changes during the 1990s as the number of rural residents moving to urban areas for employment grew rapidly. Estimates using the one percent sample from the 1990 and 2000 rounds of the Population Census and the 1995 one percent population survey suggest that the intercounty migrant population grew from just over 20 million in 1990 to 45 million in 1995 and to 79 million by 2000 (Liang and Ma, 2004). These figures likely underreport the true scale of migration because they do not account for migration that takes place over shorter periods of time (Cai et al., 2008). 
The expansion of migration over the past two decades has been facilitated by the relaxation of constraints on the household registration (hukou) system. The initial hukou reform, taking place in 1988, established a mechanism for rural migrants to obtain legal temporary residence in China's urban areas (Mallee, 1995). After rural migrants could obtain legal temporary residence, they became better able to establish networks to facilitate the job search in distant labor markets (e.g. Munshi, 2003). However, legal temporary resident status does not guarantee access to urban health and education services or social safety nets because these benefits are still linked to household registration status (World Bank, 2009). This institutional arrangement effectively discourages entire families from moving to cities. Whereas individuals with rural hukou status can now purchase nonagricultural hukou status from urban governments in many places, the system continues to work against more permanent migration flow (Fan, 2008). Migrants consequently maintain close ties with their ancestral villages.

The impacts of migration on rural households and individuals left-behind appear to be multifaceted. On one hand, remittances benefit migrant-sending households, as evidenced by their higher consumption (Du et al., 2006; de Brauw and Giles, 2008), improved risk-coping ability (Giles, 2006), and higher levels of investment in productive assets (Zhao, 2002; Woodruff and Zenteno, 2007). On the other hand, individual household members who are left behind, particularly women and seniors may be negatively affected. For example, women who live in migrant households now perform more farm work than they would have otherwise (Mu and van de Walle, 2011), and the elderly with migrant adult children are at greater risk of falling into poverty (Giles et al., 2011). Even though children's educational performance is not compromised but 
improves in migrant households (Chen et al., 2009), some nutrition measures of schoolage children are negatively affected (de Brauw and Mu, 2011).

It is important to remember that in the mid-1990s, migration rates were substantially higher among men than women for most age ranges (Zhao, 1999; Rozelle et al., 1999). Since the late 1990s more women have participated in rural-urban migration, particularly the young and the single (Du et al., 2005; de Brauw et al., 2008). In some provinces, the gender gap in migration rates is still increasing (Mu and van de Walle, 2011). Consistent with differences in migration prevalence by gender shown elsewhere, we demonstrate later in the paper that the majority of parental migration is by fathers.

\subsection{Nutritional Status of Rural Children}

China faces multiple challenges in improving nutrition among rural children. First, disparities are present in child health within and among regions. For example, undernutrition in western provinces is acute, and stunting and underweight are three times more prevalent in rural than in urban areas (UNICEF, 2008). Child growth is becoming more sensitive to household income, a consequence of increasing income inequality and the disappearance of subsidized food coupons in the mid-1990s (Osberg et al., 2009). In addition, a significant share of rural children remains malnourished. In 2002, the nationwide stunting rate was still nearly $15 \%$ (Svedberg, 2006). With inadequate access to regular micronutrient-rich diets, many rural children also suffer from iron deficiency (Luo et al., forthcoming). At the same time induced by increased income, the structure of Chinese diet is shifting away from high-carbohydrate foods toward highfat and high energy-density foods (Du et al., 2004). Consequently, overweight status has 
been increasing among children in both rural and urban areas (Monda and Popkin, 2005; de Brauw and $\mathrm{Mu}, 2011)$.

Notwithstanding these challenges, the average measures of the nutritional status of children have clearly improved over time. Economic growth is well known to be associated with improved nutritional status (Fogel, 2004), and China's experience is no exception. In 1990, the average height of children aged two to five in seven provinces was $92.5 \mathrm{~cm}$ in rural areas, an increase of $3.8 \mathrm{~cm}$ from the average in 1975 (Shen et al., 1996). Improvement in children's growth has continued since then as children's average HAZ, WAZ, and WHZ (weight-for-height z-score) increased dramatically between 1990 and 2000 (Chen, 2000; Osberg et al., 2009). These increases represent an anthropometric confirmation of significant progress in average well-being.

Some improvements in child growth are directly attributable to the progress made in public service provision. A salient example is water delivery as unsafe drinking water can cause diseases such as diarrhea, which can severely affect child growth (e.g., Glewwe and Miguel, 2008). During the 1980s, the Chinese government launched a drinking water improvement program in rural areas. Clean water from water plants substantially improves rural children's HAZ and WHZ scores (Zhang, forthcoming). In the same context, Mangyo (2008) also finds that access to in-yard water sources improves child health when mothers are relatively well educated. Even though the placement of village level water projects may be exogenous to individual decisions, household level water access may still be affected by individual demand (Mangyo, 2008). Motivated by these findings, in examining the channels through which migration may affect children's 
nutrition, we will explicitly investigate whether migration improves household access to tap water.

\section{Conceptual Framework and Literature Review}

In this section, we first describe how migration and nutritional status of children might be linked, and we further discuss results in the previous literature that attempts to examine this linkage.

Consider the migration decision for parents of children in a household. A migrant might leave because their returns to labor are higher at a potential destination than at home. Since returns to labor for the overall household unit increases, we expect income to increase. However, there are two other ramifications for the household. First, the overall time endowment of adult household members who are present decreases. So there is less time either for local production (e.g. agriculture) or for child rearing, cooking, or other activities within the household. Second, the bargaining equilibrium within the household might change. Specifically, if the household head leaves, the spouse of the head can make more decisions about resource allocations within the household, given that the head can no longer directly observe the consequences of all of those choices. Therefore, there are three main channels through which migration might affect the nutritional investment in children: the income effect, a time effect, and an effect from changes in the structure of intrahousehold bargaining and cooperation. Since these three effects might work to improve or deteriorate child nutrition, the dominant factor is an empirical question and will depend upon local conditions as well as the present status of the diet. 
An increase in household income can lead to better nutritional outcomes among children through various means. For example, higher incomes could lead to increased calorie intake if food is scarce to begin with (Fogel, 1994). The income elasticities of demand for nutritious foods, however, tend to be higher than those of coarse grains (Bouis, 1994); therefore, households may use income increases to purchase more foods rich in micronutrients (such as fruits and vegetables) and protein (such as eggs and meat) (Subramanian and Deaton, 1996; Nguyen and Winters, 2011). Diet improvements might manifest themselves in measures of nutritional status, particularly HAZ scores. However, the main channel might not be through diet improvements if the diet is already relatively adequate. Higher income could alternatively lead to improved housing conditions and a more hygienic environment, such as an environment with better access to clean water. Finally, health service utilization for children may also increase with income. The majority of rural residents were uninsured before the New Cooperative Medical Scheme was introduced in 2003, but even since 2003, out-of-pocket medical spending continues to be positively correlated with income (Wagstaff et al., 2009).

Several previous papers in the literature highlight impacts on nutritional status that likely highlight changes in income or relative income. Specifically, Azzarri and Zezza (2011) find an increase in HAZ scores in Tajikistan, which they relate to higher caloric consumption, presumably of more nutritious foods. De Brauw (2011) finds that during the food price crisis of 2008, very young children who were in households with access to migrant remittances did not experience the same decrease in HAZ scores as those that did not, presumably again because relative income was more stable for those households. Carletto et al. (2011) also study a population in rural Guatemala for which 
migrant households have higher incomes and are more food secure, leading to higher HAZ scores among young children. Mansuri (2006) finds that HAZ scores are positively correlated with migration among girls, partially due to an income effect. Finally, Gibson et al. (2011) study a Tongan population in which some children migrate with parents to New Zealand while others do not; they find that the children who migrate have higher HAZ and WAZ scores due to an improved diet.

Several studies also find evidence related to the time effect of migration. Childcare time becomes scarcer in migrant-sending households, because they are almost always engaged in some form of local production, either through farming or selfemployment. As a result, less time is allocated to cooking (Chen, 2006; de Brauw and $\mathrm{Mu}, 2011$ ) or monitoring the eating habits of children. Nobles (2007) suggests that the time endowment effect dominates in Mexico, leading children with absent fathers to have lower HAZ scores. To the extent that it is difficult and time-consuming to ensure nutritional investments in children, the time effect of migration may compromise child nutrition, especially among younger children.

Third, when household members live apart as a consequence of migration, the equilibrium in the implicit intrahousehold bargain may change. For example, some argue that wives gain increased autonomy and new decision-making powers as household heads after their husbands migrate (Davin, 1999). Considering that the empowerment of women is generally associated with better child health outcomes (e.g., Thomas, 1990; Duflo, 2003), one may expect that fathers' migration could positively affect child nutrition. Alternatively, the adult household members left behind may use more child labor in household chores but counter any potential negative effect on children by 
increasing their food intake. Such strategic behavior may result in innocuous impacts on child nutrition (Chen, 2006); one could argue that Mansuri's gender specific results for Pakistan also fit this category.

As outlined in this conceptual framework and suggested by mixed results from existing studies, whether or not parental migration affects children's health and nutrition is primarily an empirical question. In the next section we present the data and empirical framework we will use to measure this relationship in rural China.

\section{Data and Empirical Framework}

\subsection{Data}

The data used in the analysis are primarily derived from four waves of the China Health and Nutrition Survey (CHNS), collected in 1997, 2000, 2004 and 2006. ${ }^{6}$ The CHNS is a longitudinal survey covering nine provinces that vary substantially in geography, economic development, and access to public resources. ${ }^{7}$ Among other information, the survey includes the demographic characteristics and asset holdings of each household. We further make use of community-level data to account for various village characteristics.

Important for this paper, the CHNS records: height and weight for each individual within the household, measured by a physician, nurse or a health worker during the survey. We measure nutritional status through three measures based on height and weight: HAZ-scores, WAZ scores, and BMIZ scores. HAZ scores specifically measure the cumulative investments that parents have made in children over time, and are

${ }^{6}$ See http://www.cpc.unc.edu/projects/china for details.

${ }^{7}$ The nine provinces are Henan, Hubei, Heilongiiang, Liaoning, Shandong, Guizhou, Jiangsu, Guangxi, Hunan. 
particularly sensitive to investments made while children are younger than two years old (WHO, 1983; Schroder et al., 1995). BMIZ scores fluctuate more contemporaneously with changes in diet or and can therefore highlight short-term changes in nutrition. WAZ scores to some extent confound the two (short term and cumulative nutrition), though reflect the changes in shorter term nutritional status among younger children. To construct HAZ, WAZ, and BMIZ scores, we use the most recent growth charts made available by the WHO, which have corrected previous standard growth charts for what are now considered developed-country biases (de Onis et al., 2007). ${ }^{8}$

The migration status of household members in CHNS can be built up from the household roster. Starting from 1997, if an individual who was in a previous round of the CHNS is not residing in the same household in the current survey, a question is asked regarding the reasons for his/her absence. We consider any individual who has left the home to seek employment at the time of the survey to be a migrant. ${ }^{9}$ This definition differentiates migration for work from migration for other reasons, but it could underreport the migration rate because return migrants cannot be identified. Hence, we may underestimate the impact of parents' migration on children's nutrition status. On average, at the time of each survey migrants had been away from home for about 14 months. As our instrumental variables are suited for identifying the impact of migration per se and not of the lengths of the migration spell, our results below provide estimates of the average impact of migration.

\footnotetext{
${ }^{8}$ See http://www.who.int/childgrowth/en/ and http://www.who.int/growthref/en/ for details on the growth reference data, which are consistent with one another.

${ }^{9}$ Unfortunately, the CHNS lacks information on remittances back to households from migrants. Therefore we measure the net effect of migration, meaning the variable is the net effect of all effects of migration on the household (including any remittances received).
} 
We pool panel data from all three pairs of surveys - 1997 and 2000; 2000 and 2004; 2004 and 2006 - and keep sample children aged under 5 years in the initial years (1997, 2000, and 2004) and surveyed for two consecutive rounds in our analysis. Our focus on young children is motivated by the findings that they are at greater risk for problems associated with malnutrition and are more likely to respond to nutrition interventions (WHO, 1995). With two observations for each child, we can apply panel data analysis to control for time-invariant individual, family, and community characteristics.

Trends related to migration and anthropometric measures found in the literature, discussed in Section 2, are also present in the CHNS. To illustrate migration trends, we graph locally weighted regressions of out-migration on age for individuals aged 16 to 75 (Figure 1). Age is negatively correlated with the probability of out-migration for both men and women. Except for the oldest age cohorts, migration prevalence among individuals of any given age increases over time among both men and women. The rate of increase is slower among older individuals, implying that migrant labor flows tend to be young, consistent with findings in other studies (e.g., Liang and Ma, 2004). In the 25to 40-year-old range, migration rates tend to increase among younger workers, more likely to be married and with children, from around 10 percent for men in 1997 to between 30 and 35 percent in 2006. For women, increases in migration are less dramatic, from less than 10 percent in 1997 to above 20 percent in 2006 . It could reasonably be expected that migration by individuals in these cohorts have the largest chance of affecting the nutritional status of children. 
Consistent with the evidence previously presented in Figure 1, over time more children in our sample are found to be living in migrant households (Table 1). Whereas 6 percent of children had a migrant parent in 1997, by 2006 this figure increased to nearly 34 percent. Most parental migration in China is done by fathers: migration by the father alone increases from 3.4 percent in 1997 to 13.3 percent of households in 2006. In later rounds, it is increasingly common to observe both parents migrating - this case is found among 10 percent of children in 2004 and among 15.7 percent of children in 2006. For a small proportion of children, the mother is a sole migrant. With panel data, we can observe changes in parental migration status. In 2000 and 2004, about 3 percent and 11 percent more children become a part of migrant household, respectively. Approximately 20 percent of the children had a parent who migrated in 2006, but had not as of 2004. In Figure 2, we present locally weighted regressions of HAZ, WAZ, and BMIZ for children younger than 10. On average HAZ and WAZ tend to increase over time at most ages, suggesting improvements to child nutrition. In 1997, the average HAZ is under -1, implying a significant stunting rate. ${ }^{10}$ By 2006, the average HAZ score increases to around -0.7 , with the scores of the very young children approaching those of the healthy reference population. The age profile of HAZ shows that this measure deteriorates from birth to approximately 48 months. After that the average HAZ levels off or improves slightly. This pattern is similar to that found in Guatemala (Carletto et al., 2011), where the turning point is around 30 months. WAZ is negatively correlated with age, a pattern common in many developing countries, such as El Salvador (de Brauw, 2011). A steady increase in WAZ is evident during the period between 1997 and 2006. Children younger than 3 have already had average WAZ equal to or above the international norm in 2006.

\footnotetext{
${ }^{10}$ Children with an HAZ below -2 are considered "stunted."
} 
Given that WAZ scores for most children in the sample are higher than their HAZ scores, it is not surprising that BMIZ scores are actually higher than international norms on average until children reach age 5. Children in rural China therefore appear to be getting enough food to eat, but the food they eat is not rich enough in micronutrients to achieve HAZ scores that reach international norms on average.

We explore the differences in distribution of these anthropometric measures between children with at least one migrant parent and those whose parents who did not migrate at the time of the survey. Figure 3 shows that the middle of the distribution of HAZ for children whose parents did not migrate is positioned slightly right to that for children with a migrant parent, but no distinct shift in the whole distribution is observed. The distributions of WAZ and BMIZ exhibit a similar pattern for these two groups of children.

\subsection{Empirical Framework}

The conceptual framework in Section 3 suggests estimating an equation for nutritional outcomes of individual child $i$ in household $h$ of village $j$ at time $t$ denoted by $H_{i h j t}$. It is a function of parents' migration status $\left(M_{h j t}\right)$, which is measured as a dummy variable equal to 1 if at least one parent has migrated out at time $t$, and 0 otherwise; the age and gender of the child in the initial period $\left(A_{i h j 0}\right)$; household $\left(X_{h j t}\right)$ and village $\left(V_{j t}\right)$ characteristics; province-specific year effects $Y_{p \times t}$; and individual fixed effects $\left(\mu_{i}\right)$. The inclusion of $\mu_{i}$ effectively controls for such important determinants of child height and weight as maternal height (Ozaltin, Hill and Subramanian, 2011). To account for the way children grow as they age in the early years, we allow age and gender effects to vary over 
time by interacting $A_{i h j 0}$ with a time trend T. With the idiosyncratic error term denoted as $\varepsilon_{i h j t}$, the estimation equation can be written as follows:

$$
H_{\text {ihjt }}=\alpha_{0}+\alpha_{1} M_{h j t}+A_{i h j 0} T \alpha_{2}+X_{h j t} \alpha_{3}+V_{j t} \alpha_{4}+Y_{p \times t}+\mu_{i}+\varepsilon_{i h j t}
$$

Our conceptual framework suggests that controlling for heterogeneity between households and villages is likely to be important in explaining nutritional outcomes among children. To this end, the rich information in the CHNS is very useful because it allows us to include a large set of control variables in the regression analysis. Specifically, the $X_{h j t}$ vector includes the years of education of the household head, the number of senior (aged 60 and above) and working age (aged 16 to 59) household members by gender, household size, and household assets per capita. ${ }^{11}$ We include an indicator for the presence of a health clinic in the village and the share of other households in the village that have tap water in the vector of village characteristics $\left(V_{j t}\right)$. We also include the village-level average income to account for wealth effects within the community brought about by migration network. In addition, we control for market prices of rice, flour, and pork as through relative wealth and household diet, food prices may influence migration decisions as well as the nutritional status of children. Finally, the province-time fixed effects $\left(Y_{p \times t}\right)$ control for time-varying macroeconomic conditions that differ by provinces.

\footnotetext{
${ }^{11}$ We include the self-reported values of the following types of assets in the calculation of total asset values: productive assets (transportation means, farm machineries, draft animals, commercial equipment), household electrical appliances (radio, tape recorder, VCR, black/white television, color television, washing machine, refrigerator, air conditioner, sewing machine, electric fan, computer, camera, microwave oven, electric rice cooker, pressure cooker, telephone, VCD or DVD). Only $4.6 \%$ of the households reported zero assets. When we take the logarithm of the asset value, we assign a value of 1 to those households.
} 
With this large set of control variables, we still cannot rule out that unobservable traits of a child, such as innate health, can affect both the migration decision of their parents and their growth outcomes. With panel data, a reasonable way of controlling for individual-level fixed effects is to difference the two periods. After differencing equation (1), we can write the following:

$$
\Delta H_{i h j t}=\alpha_{1} \Delta M_{h j t}+A_{i h j 0} \alpha_{2}+\Delta X_{h j t} \alpha_{3}+\Delta V_{j t} \alpha_{4}+\Delta Y_{p \times t}+\Delta \varepsilon_{i h c t}
$$

In estimating equation (2), any effect of migration on children's nutritional outcomes is identified off changes in migration status among households occurring between survey rounds; however, we must still be concerned that unobservables that vary over time may be important determinants of child nutrition as well as household migration decisions. Clearly, such variables are not accounted for in equation (2). For example, income shocks resulting from crop failures could affect both migration decisions and the diets of children (or other factors that influence their nutritional status).

To identify the causal impact of migration, we must find variables that affect migration but do not independently affect children's nutritional status. In this context, we suggest the following identification strategy. We hypothesize that wage growth in provincial capital cities $\left(\Delta W_{p t}\right)$ potentially affects household migration decisions. A large share of migration during 1990-2000 is intraprovincial (72.3\% in 1990 and $46.1 \%$ in 2000) (Liang and Ma, 2004). Even though the interprovincial migration, responsive to the increasing interregional disparities, has gone up over time, according to CHNS more than one third of the migrants move within provincial borders. Wage growth in the provincial capital city therefore could proxy for the demand side signal that migrants would observe. The CHNS community survey contains information for each primary 
survey unit on the daily wage for an ordinary male and female worker separately. Using the mean reported wages for each capital city, we calculate the wage growth between survey years.

We further hypothesize that the strength of the wage signal in cities will also be affected by the initial size of the household migrant network $\left(M_{-h j 0}\right)$, as measured in the 1997 survey. ${ }^{12}$ We exclude household $h$ when calculating its network (denoted by $-h$ ). More specifically, it is measured as the share of men and women between the ages of 18 and 45 who had migrated in $1997 .^{13}$ The change in migration can therefore be written as follows:

$$
\Delta M_{h j t}=f\left(\Delta W_{p t}\right)+r M_{-h j 0}+M_{-h j 0} \times f\left(\Delta W_{p t}\right)
$$

It is conceivable that wage growth and the migrant network individually affect migration decisions; each variable on their own might also be correlated with children's nutrition outcomes even after we account for migration. For example, wage growth in the provincial capital might be correlated with changes in local wages, which could be reflected in changes in anthropometric measures through the income effect. Households with large migrant networks might have better access to nutrition information affecting anthropometric outcomes independently of migration. Once we control for the migration network and the provincial capital wage growth directly in the regression, the variation in the interaction term is unlikely to independently affect children's anthropometric outcomes. In equation (2), we implicitly control for wage growth $\left(\Delta W_{p t}\right)$ through the province-specific year effect $\left(\Delta Y_{p \times t}\right)$ and migration network $\left(M_{-h j 0}\right)$ through fixed

\footnotetext{
${ }^{12}$ The reasons for absence were recorded only from the 1997 round onward, so we cannot use earlier waves to construct the instrumental variables. For villages in Liaoning province, which were added to the survey in 2000 , the 2000 migration rates are used to measure the migrant network.

${ }^{13}$ In the sample, each village on average has about 48 women and 49 men in this age group.
} 
effects. The interaction term alone $\left(\Delta W_{p t} \times M_{-h j 0}\right)$ is therefore used for statistically identifying migration.

Given wage growth, migration is more likely among individuals with larger migrant networks, and their children are more likely to be left behind. This relationship is confirmed in Figure 4, in which we stratify villages into two groups: a group with larger migrant networks and a group with smaller migrant networks. We define the cutoff for large migrant networks as villages with at least 15 percent of working-age women or 20 percent of working-age men migrating in 1997. The graphs illustrate that in villages with larger migrant networks, migration responds positively with wage growth, but the relationship between migration and urban wage growth is much weaker in villages with smaller migrant networks. Moreover, this pattern holds for both men and women. This approach essentially exploits the complementarity between urban wage and migrant network in an individual's migration decision. Under the assumption that the interaction variable is independent of $\Delta \varepsilon_{i h c t}$ in equation (2), our estimate of $\alpha_{1}$ would be unbiased. We primarily test this assumption by checking the robustness of the estimates to the inclusion of various sets of variables that might confound the relationship between migration and the interaction variable. Through this approach, the impacts identified are local average treatment effects, that is, the migration effects of those parents who rely on initial migrant networks for job searches and are pulled by wage growth in the provincial capital city.

\section{Results}

\subsection{Primary Results}


We first examine the three anthropometric measures (HAZ, WAZ, and BMIZ) as dependent variables and estimate equations (1) and (2), respectively, treating parental migration as exogenous. The results are reported in Table 2.

Both the OLS and the first differenced models yield insignificant coefficients on the migration variable. The results suggest that parental migration status may not affect children's nutrition status. But these point estimates are likely to be biased because they do not account for the endogeneity of migration.

Considering covariates, we find that the correlation between age and anthropometric status differ by estimation strategy: age specific time trends are statistically significant for the three z-scores in OLS, and but only significant for multiple trends for HAZ scores in the first differences. The household head's years of schooling, the number of working-age women, household assets, and the percentage of other households in the village having tap water are shown to be positively correlated to children's HAZ, but these correlations cease to be statistically significant when we take the first difference. Consistent across the two sets of results, household assets are shown to be positively associated with WAZ. In first differences, the results also suggest that the number of female household members aged 60 and above is positively correlated with WAZ and BMIZ scores.

Next, we use the interaction terms described above as instrumental variables for migration to reestimate equation (2) and present the results in Table 3 . The instruments are gender-specific interactions between wage growth in the provincial capital and the household initial migration network. For each outcome variable, we present the first stage estimation first followed by the results from the second stage. With the full set of 
control variables for age and gender of the child, household characteristics, and village characteristics, we find that the instruments are strongly correlated with changes in parent migration status. The overidentification tests are passed comfortably. The F statistics on the joint test that both coefficients are zero are above 6 for all three regressions. Under standard assumptions about the error terms, the instruments would be considered weak (e.g. Stock and Yogo, 2005). However, in the presence of clustering, it is less clear though whether the F statistics suggest weak instruments. We therefore provide the 95 percent confidence intervals based on Moreira's (2003) weak instrument robust conditional likelihood ratio statistics. The statistics are adjusted for clustering and robust to weak instruments (Finlay and Magnusson, 2009).

In the second stage, we find no significant relationship between the migration variable and child HAZ scores. The interval for HAZ scores suggests that the null hypothesis of no relationship cannot be rejected at the 5 percent significance level. As expected, relative to the OLS and first differenced results the standard errors rise, whereas the point estimate remains small. Consistent with results reported in Table 2, these results confirm that parental migration does not affect children's HAZ scores. When we estimate the model using changes in WAZ scores as the dependent variable, we find a statistically significant coefficient of reasonable magnitude: 0.190 standard deviations. This estimate essentially suggests that the children of migrants are heavier than children of others, ceteris paribus. Even if the point estimate may suffer from weak instrument bias, the 95 percent interval is positive throughout its range, suggesting migration has an unambiguously positive impact on WAZ scores. We find a point estimate of 0.105 for parental migration status on BMIZ, but it is not statistically different 
from zero. Given the absolute lack of significance when using HAZ scores as the dependent variable, migration does not appear to affect the long-term nutritional measure, but the short-term measures. In fact, the 95 percent confidence interval for the coefficient estimate on BMIZ is primarily positive, adding support to this argument. Therefore, our inability to reject the null hypothesis that the coefficient estimate of the BMIZ scores is zero is likely the result of a lack of statistical power in the regression.

In summary, our primary regression results indicate that parental migration has a positive effect on children's weight but has no impact not height. Next we check the robustness of our estimates to potential misspecifications and confounding factors.

\subsection{Robustness Checks}

One of the primary concerns about our results is that changes in household characteristics may be endogenous to children's nutritional status. For example, the change in household assets may be correlated with unobserved shocks that could also affect changes in children's nutritional outcomes; moreover, asset changes or changes in household demographic compositions may also be associated with the migration decisions of household members. Such correlation may lead to biased estimates of migration. To rule out the possibility that the above results are driven by changes in endogenous household characteristics, we estimate the regressions without including household characteristics as control variables. The results are reported in Table 4.

Compared to the previous estimates with household level control variables, the coefficients on migration in Table 4 are smaller in all three regressions. The influence of controlling for household wealth and demographic changes on the relationship between 
migration and nutritional status is ambiguous. On one hand, parental emigration is likely to correlate positively with the number senior household members because more small children live with a grandparent in migrant households than in non-migrant households (de Brauw and Mu 2011). As the number of senior female household members appears positively correlated with children's nutritional outcomes (Table 2), the estimated migration effect would be larger without household demographic variables. On the other hand, households may increase out-migration in response to negative wealth shocks (Giles and Yoo, 2007), constituting a negative correlation between migration and household assets. Whereas household wealth is positively associated with child nutrition, without asset variable the estimated effect of migration would be smaller. Albeit the change in magnitude of the coefficient on migration, the results are consistent with the previous finding that parental emigration positively affects children's weight but not their height.

We are also concerned about potential panel attrition bias. The CHNS sample attrition is high for children aged 0 to 5, particularly between 2004 and 2006 (Table 5). If the attrition is systematically correlated with children's nutrition status and parental migration decision, then the estimation based on the remaining panel would be biased. In Table 5 we compare these variables between children who were surveyed in two consecutive rounds with those who dropped after the initial years, and we find neither statistically significant differences in average anthropometric scores measured in the initial years nor differences in the propensity to come from a migrant household. With respect to these observables the panel attrition would therefore appear to be random. 
Nonetheless, we reestimate the main IV regressions using a correction for attrition as follows. First, we estimated the probability that individuals stayed in the sample, given initial characteristics of individuals (results reported in Appendix Table 2). We subsequently use the inverse of that estimated probability as a weight in the regressions (Wooldridge, 2010). The intuition is that by giving more weight to children who appear less likely to remain in the sample, we make the analysis sample more representative of the original one. Continuing to control for the full set of other explanatory variables (Table 7), we find that the results are largely unchanged. The estimate for the effect of migration on WAZ scores is statistically significant, but not for BMIZ or HAZ scores. ${ }^{14}$

\subsection{Mechanisms}

Given the pattern of results, we want to understand how migration might have affected children's weight. The potential pathways we choose to examine is limited and determined by information available in the data. Our first focus is children's food intakes, because weight and height could be affected by an increase in the quantity and quality of food consumed, as discussed earlier. Unfortunately we are unable to estimate the effects of migration on caloric intake or the share of calories consumed from carbohydrates, protein and fat in a framework outlined in equation (2), because the overidentification tests invalidate the instrumental variables in those regressions. ${ }^{15}$

A second potential mechanism for increased weight-for-age discussed in section 3 is through improved housing environment. We estimate equation (2) using two measures of housing conditions: the presence of an in-house flush toilet, and the presence of in-

\footnotetext{
${ }^{14}$ Limited by the sample size, we are not able to precisely estimate heterogeneous impacts along the gender or poverty dimension.

${ }^{15}$ The regression results are not reported here, but are available from the authors upon request.
} 
house or in-yard tap water (Table 7). We find no statistically significant relationship between migration and having a flush toilet in the house, but we find that households with migrants are 7 percentage points more likely to have a water tap in the house or in the yard than households without migrants. For the estimated migration effect, the 95 percent confidence interval based on the weak instrument robust conditional likelihood ratio test includes 0 ; however, the minimum value is -0.001 . So we take the result as suggestive evidence that migration helps improve the household tap water connection.

In our sample, households in about $20 \%$ of the communities have no tap water at all, but the share of communities where all households have tap water has increased from $33 \%$ to $52 \%$ between 1997 and 2006. The improvement is in part a result of investments in community water supply infrastructure, as community fixed effects can explain $58.2 \%$ of the variation in household tap water connections. But community infrastructure is not the single determining factor of access to tap water. In some communities, the tap water connection is either a household initiative or based on household demand. Our results indicate that in such communities, compared to households without a migrant, migrant households are more likely to have in-house or in-yard tap water.

Finally, we find no relationship between parental migration and child healthcare utilization, namely immunization and physical check-ups. So it seems that the only plausible mechanism we can identify is through increases in the availability of tap water.

\section{Conclusions}

In this paper, we study the effects of parent migration on young children's nutritional status in rural China. We find that migration is positively associated with 
short-term measures of nutritional status. According to our within-individual differenced and instrumented results, parent migration is associated with an increase of WAZ-scores of between 0.08 and 0.2 standard deviations. The estimated coefficients on HAZ and BMIZ-scores are positive, but not significantly different from zero. These basic results are robust to different specifications and to a standard correction for panel attrition. In exploring possible mechanisms through which these impacts might occur, we provide suggestive evidence that migrant households are more likely to have tap water, which is likely to reflect an income effect.

The estimates are average impacts of migration. Heterogeneities in terms of the timing of migration are not studied in this paper, but deserve further research. Even though our results indicate that young children's nutritional status does not seem to be compromised by the absence of their parent(s), we are not optimistic that children left behind can benefit unambiguously from parental migration. First, our previous study (de Brauw and $\mathrm{Mu}, 2011$ ) shows that once children grow, they take up additional household chores. Any advantage they may have in weight for age when young may disappear. Second, the anthropometric measures, although easy to gauge, do not capture many important dimensions of health. For example, they cannot account for any psychological impacts of parental migration on children.

However, it is important to note that migration seems to have a positive impact on household consumption of public goods, such as tap water. Further research is needed to analyze the mechanisms through which such investments occur, or more generally how migration is related to the provision and use of public goods. 
Figure 1. Migration rate by gender and year: China Health and Nutrition Survey, 1997-2006

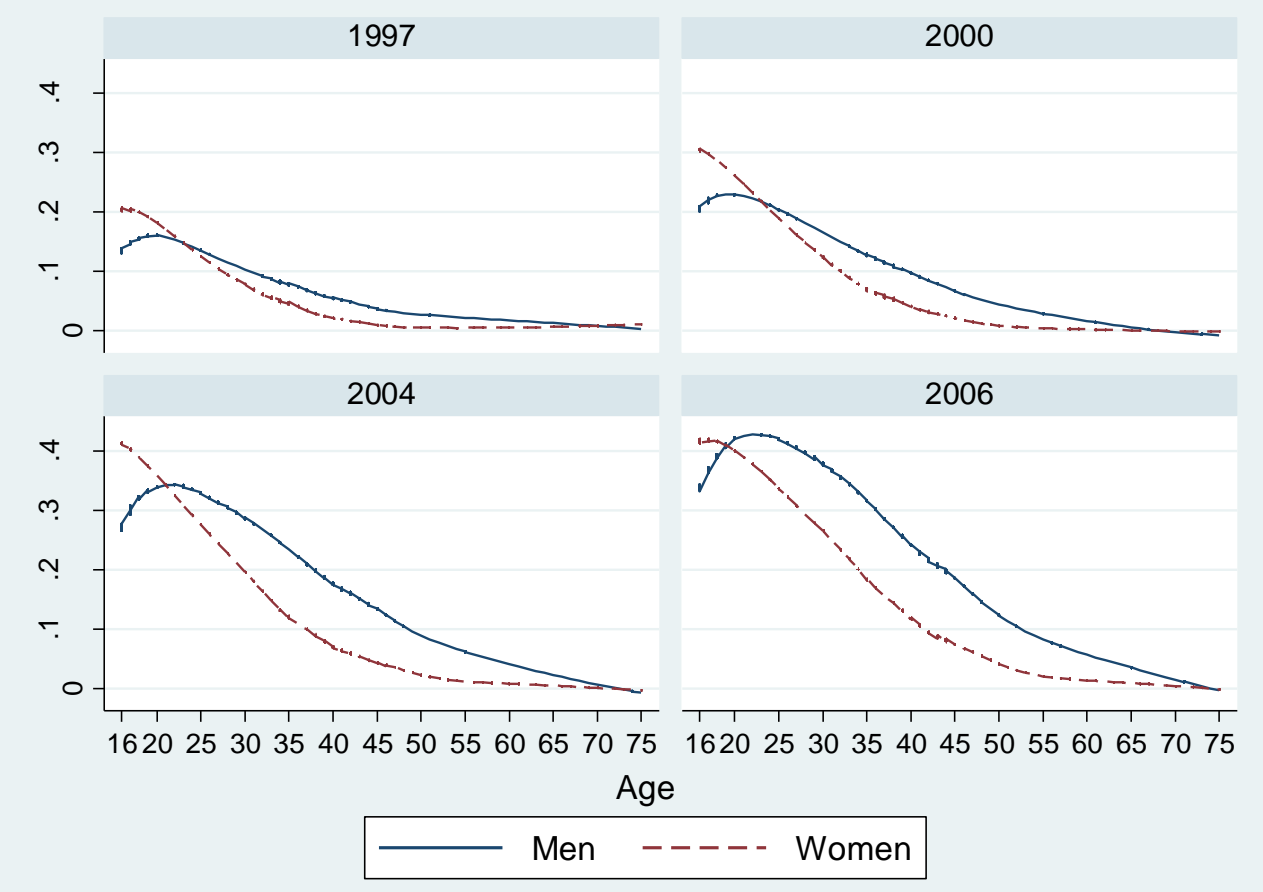


Figure 2. Nutritional outcomes of children aged 0-9 by year: China Health and Nutrition Survey, 1997-2006
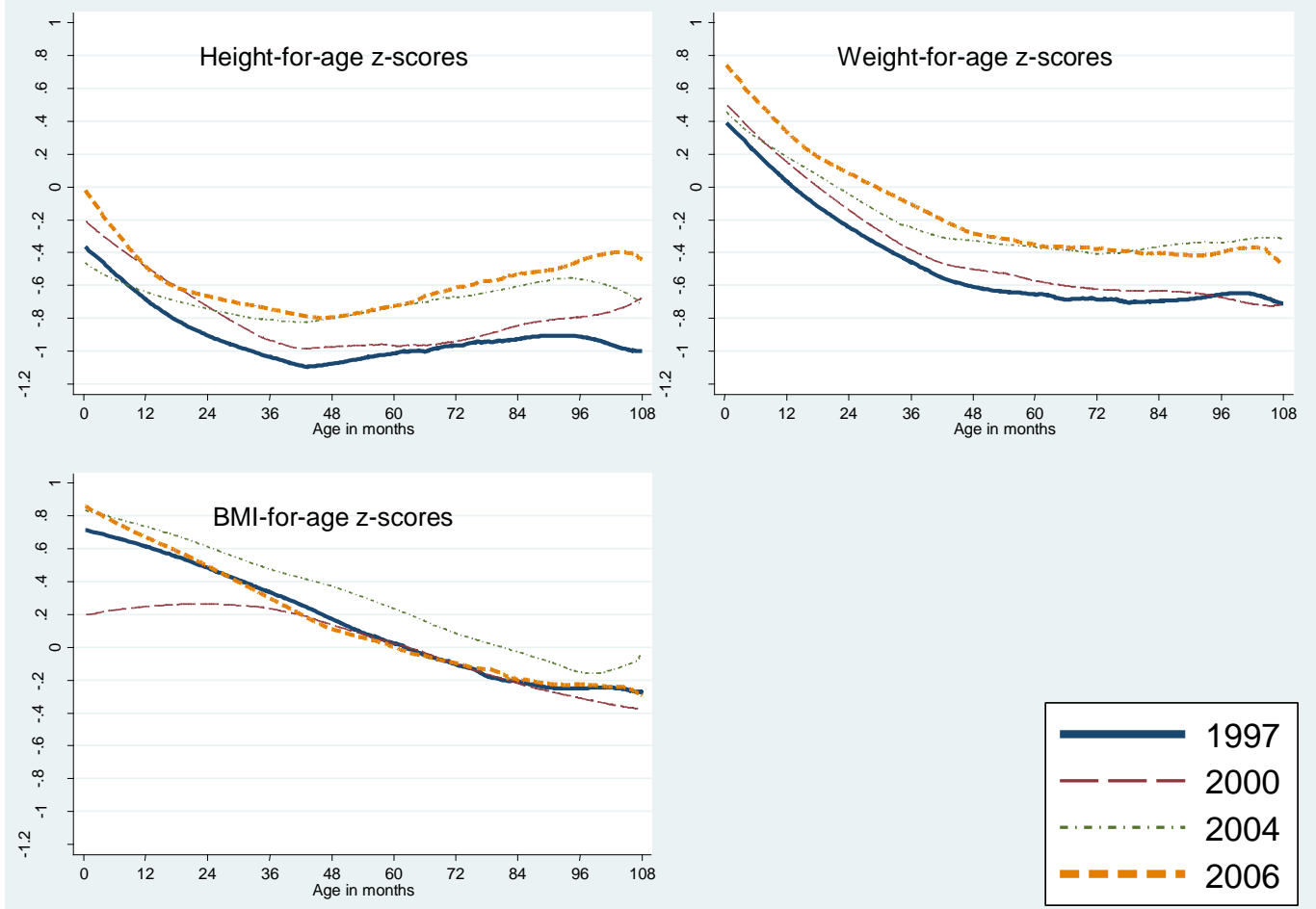
Figure 3. Nutritional outcomes of children Aged 0-9 by parent migration status: China Health and Nutrition Survey, 1997-2006
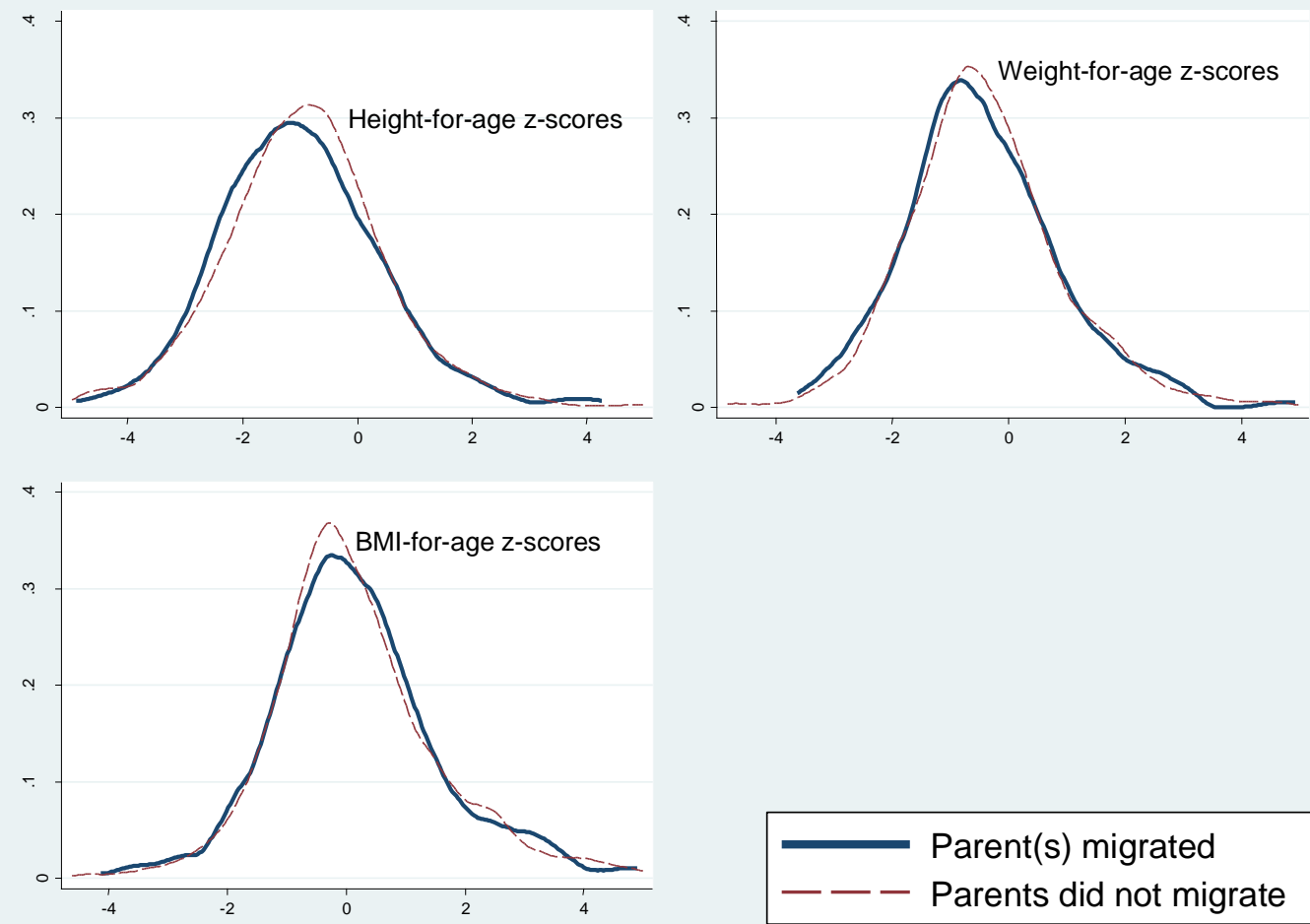
Figure 4. Share of children in migrant households and wage growth in provincial capital, by village initial migrant network: China Health and Nutrition Survey, 1997-2006

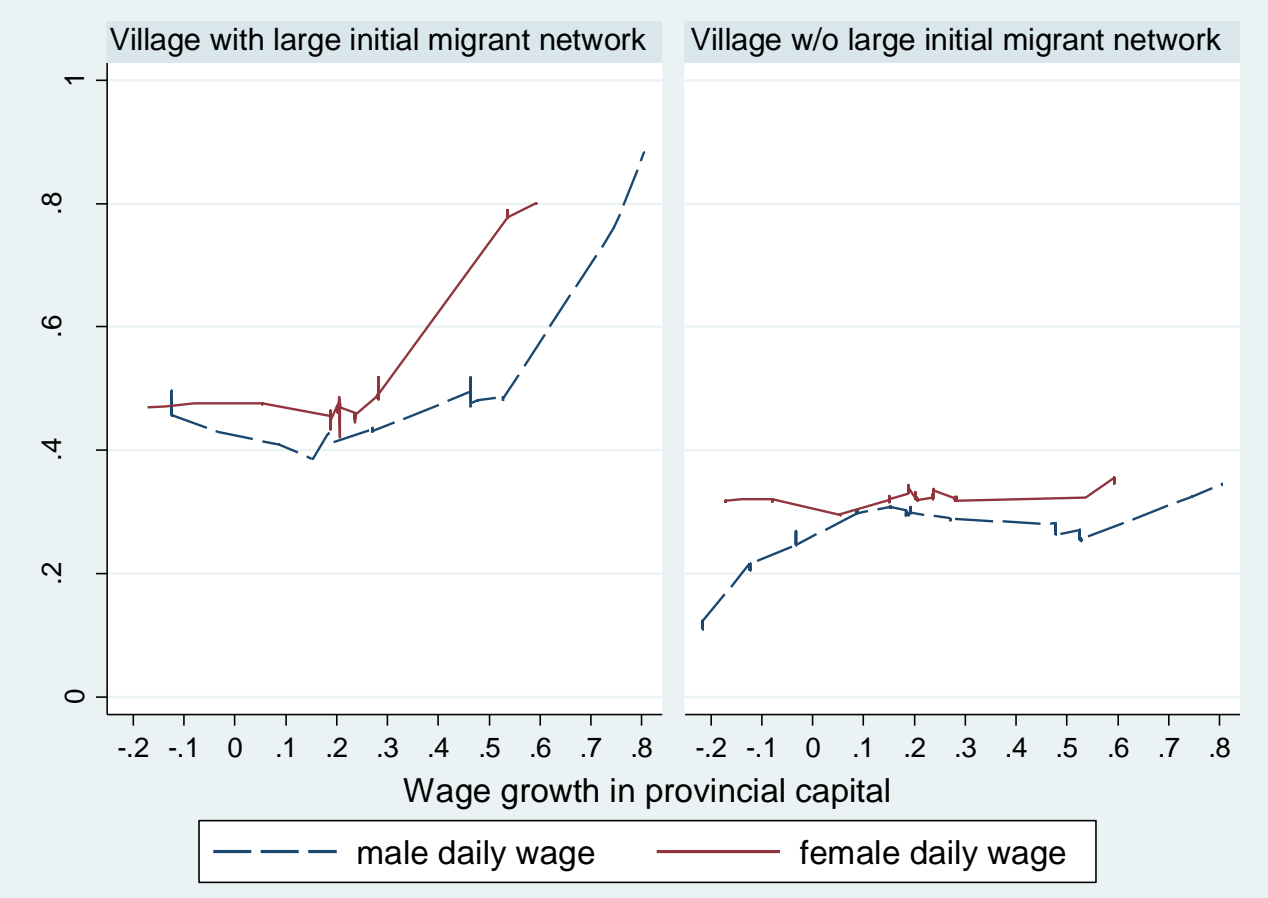

Note: "Villages with large initial migrant network" are defined as villages in which $15 \%$ of working-age women or $20 \%$ working-age men migrated in initial years. The rest of the villages are labeled as "villages without large initial migrant network". 
Table 1. Migration of parents of rural children: China Health and Nutrition Survey, 1997-2006

\begin{tabular}{|c|c|c|c|c|}
\hline & $\begin{array}{c}1997 \\
\text { (aged 0-5) }\end{array}$ & $\begin{array}{c}2000 \\
\text { (age } 0-8)\end{array}$ & $\begin{array}{c}2004 \\
\text { (age } 0-9)\end{array}$ & $\begin{array}{c}2006 \\
\text { (age 2-7) }\end{array}$ \\
\hline \multirow{2}{*}{ Any Parent Migrated } & 0.060 & 0.116 & 0.231 & 0.337 \\
\hline & $(0.238)$ & $(0.320)$ & $(0.422)$ & $(0.476)$ \\
\hline \multirow{2}{*}{ Father Migrated Only } & 0.034 & 0.069 & 0.090 & 0.133 \\
\hline & $(0.181)$ & $(0.254)$ & $(0.286)$ & $(0.341)$ \\
\hline \multirow{2}{*}{ Mother Migrated Only } & 0.009 & 0.019 & 0.040 & 0.047 \\
\hline & $(0.092)$ & $(0.136)$ & $(0.197)$ & $(0.213)$ \\
\hline \multirow{2}{*}{ Both Parents Migrated } & 0.017 & 0.027 & 0.100 & 0.157 \\
\hline & $(0.130)$ & $(0.163)$ & $(0.300)$ & $(0.366)$ \\
\hline \multirow{2}{*}{ Any Parent Newly Migrated } & & 0.028 & 0.113 & 0.197 \\
\hline & & $(0.167)$ & $(0.317)$ & $(0.401)$ \\
\hline Number of Obs. & 239 & 479 & 325 & 85 \\
\hline
\end{tabular}

Note: Standard deviations are in parenthesis. Rural children who were aged 0-5 in 1997, 2000 or 2004 and surveyed in CHNS for at least two consecutive rounds with non-missing anthropometric measures are included in the calculation. 
Table 2. Baseline regressions of height-for-age, weight-for-age, and BMI-for-age z-scores, China Health and Nutrition Survey, 1997-2006

\begin{tabular}{|c|c|c|c|c|c|c|}
\hline & \multicolumn{3}{|c|}{ OLS } & \multicolumn{3}{|c|}{ First Differences } \\
\hline & HAZ & WAZ & BMIZ & HAZ & WAZ & BMIZ \\
\hline Parent(s) migrated & $\begin{array}{c}0.009 \\
(0.178)\end{array}$ & $\begin{array}{c}-0.0646 \\
(0.142)\end{array}$ & $\begin{array}{l}-0.105 \\
(0.143)\end{array}$ & $\begin{array}{l}-0.065 \\
(0.177)\end{array}$ & $\begin{array}{l}-0.010 \\
(0.011)\end{array}$ & $\begin{array}{c}0.164 \\
(0.189)\end{array}$ \\
\hline \multicolumn{7}{|l|}{ Individual Characteristics } \\
\hline Boy $\times$ Time Trend & $\begin{array}{l}0.043^{*} \\
(0.022)\end{array}$ & $\begin{array}{c}0.061 * * * \\
(0.021)\end{array}$ & $\begin{array}{c}0.029 \\
(0.027)\end{array}$ & $\begin{array}{l}-0.041 \\
(0.031)\end{array}$ & $\begin{array}{l}-0.002 \\
(0.025)\end{array}$ & $\begin{array}{l}-0.039 \\
(0.033)\end{array}$ \\
\hline One year old $\times$ Time Trend & $\begin{array}{l}-0.007 \\
(0.036)\end{array}$ & $\begin{array}{c}0.012 \\
(0.029)\end{array}$ & $\begin{array}{l}-0.019 \\
(0.038)\end{array}$ & $\begin{array}{c}0.109 \\
(0.094)\end{array}$ & $\begin{array}{c}0.023 \\
(0.097)\end{array}$ & $\begin{array}{c}0.116 \\
(0.120)\end{array}$ \\
\hline Two years old $\times$ Time Trend & $\begin{array}{c}0.056 \\
(0.036)\end{array}$ & $\begin{array}{c}0.029 \\
(0.030)\end{array}$ & $\begin{array}{l}-0.049 \\
(0.039)\end{array}$ & $\begin{array}{c}0.240 * * \\
(0.100)\end{array}$ & $\begin{array}{c}0.091 \\
(0.090)\end{array}$ & $\begin{array}{l}-0.029 \\
(0.102)\end{array}$ \\
\hline Three years old $\times$ Time Trend & $\begin{array}{l}0.057^{*} \\
(0.029)\end{array}$ & $\begin{array}{c}0.023 \\
(0.030)\end{array}$ & $\begin{array}{c}-0.081 * * \\
(0.039)\end{array}$ & $\begin{array}{l}0.186^{*} \\
(0.101)\end{array}$ & $\begin{array}{c}0.120 \\
(0.107)\end{array}$ & $\begin{array}{c}0.005 \\
(0.106)\end{array}$ \\
\hline Four years old $\times$ Time Trend & $\begin{array}{c}0.005 \\
(0.038)\end{array}$ & $\begin{array}{l}-0.041 \\
(0.030)\end{array}$ & $\begin{array}{c}-0.110 * * * \\
(0.037)\end{array}$ & $\begin{array}{l}0.188^{*} \\
(0.101)\end{array}$ & $\begin{array}{c}0.127 \\
(0.096)\end{array}$ & $\begin{array}{c}0.032 \\
(0.111)\end{array}$ \\
\hline Five years old $\times$ Time Trend & $\begin{array}{c}0.056 \\
(0.177)\end{array}$ & $\begin{array}{c}-0.317 * * \\
(0.137)\end{array}$ & $\begin{array}{c}-0.661 * * * \\
(0.153)\end{array}$ & $\begin{array}{l}0.558^{*} \\
(0.290)\end{array}$ & $\begin{array}{l}0.535^{*} \\
(0.280)\end{array}$ & $\begin{array}{c}0.270 \\
(0.354)\end{array}$ \\
\hline \multicolumn{7}{|l|}{ Household Characteristics } \\
\hline Head's years of schooling & $\begin{array}{c}0.038 * * \\
(0.018)\end{array}$ & $\begin{array}{c}0.0235 \\
(0.0171)\end{array}$ & $\begin{array}{c}0.000 \\
(0.018)\end{array}$ & $\begin{array}{c}0.012 \\
(0.017)\end{array}$ & $\begin{array}{c}-0.014 \\
(0.012)\end{array}$ & $\begin{array}{l}-0.011 \\
(0.015)\end{array}$ \\
\hline No. of female aged 60 and above & $\begin{array}{c}0.333 * * \\
(0.154)\end{array}$ & $\begin{array}{c}0.168 \\
(0.130)\end{array}$ & $\begin{array}{l}-0.058 \\
(0.138)\end{array}$ & $\begin{array}{c}0.059 \\
(0.188)\end{array}$ & $\begin{array}{c}0.367 * * * \\
(0.128)\end{array}$ & $\begin{array}{l}0.420 * \\
(0.224)\end{array}$ \\
\hline No. of male aged 60 and above & $\begin{array}{l}-0.013 \\
(0.193)\end{array}$ & $\begin{array}{l}0.0157 \\
(0.183)\end{array}$ & $\begin{array}{c}0.010 \\
(0.170)\end{array}$ & $\begin{array}{c}0.236 \\
(0.236)\end{array}$ & $\begin{array}{l}-0.289^{*} \\
(0.174)\end{array}$ & $\begin{array}{l}-0.180 \\
(0.185)\end{array}$ \\
\hline No. of working-age men & $\begin{array}{l}-0.077 \\
(0.104)\end{array}$ & $\begin{array}{l}-0.0550 \\
(0.0798)\end{array}$ & $\begin{array}{c}0.019 \\
(0.085)\end{array}$ & $\begin{array}{c}0.104 \\
(0.104)\end{array}$ & $\begin{array}{l}-0.108 \\
(0.088)\end{array}$ & $\begin{array}{c}0.093 \\
(0.117)\end{array}$ \\
\hline No. of working-age women & $\begin{array}{c}0.289 * * * \\
(0.105)\end{array}$ & $\begin{array}{l}0.215^{* *} * \\
(0.0908)\end{array}$ & $\begin{array}{c}0.019 \\
(0.086)\end{array}$ & $\begin{array}{l}-0.072 \\
(0.129)\end{array}$ & $\begin{array}{c}0.061 \\
(0.091)\end{array}$ & $\begin{array}{c}0.150 \\
(0.099)\end{array}$ \\
\hline
\end{tabular}




\begin{tabular}{|c|c|c|c|c|c|c|}
\hline & \multicolumn{3}{|c|}{ OLS } & \multicolumn{3}{|c|}{ First Differences } \\
\hline & HAZ & WAZ & BMIZ & HAZ & WAZ & BMIZ \\
\hline Household assets per capita (log) & $\begin{array}{c}0.130^{* * * *} \\
(0.041)\end{array}$ & $\begin{array}{c}0.0846 * * \\
(0.0423)\end{array}$ & $\begin{array}{l}-0.017 \\
(0.040)\end{array}$ & $\begin{array}{c}0.024 \\
(0.035)\end{array}$ & $\begin{array}{c}0.104 * * * \\
(0.034)\end{array}$ & $\begin{array}{c}0.060 \\
(0.040)\end{array}$ \\
\hline
\end{tabular}

\section{Village Characteristics and Food Prices}

\begin{tabular}{lcccccc} 
Average income per capita (log) & 0.002 & -0.0426 & -0.091 & 0.113 & 0.082 & 0.091 \\
& $(0.091)$ & $(0.119)$ & $(0.110)$ & $(0.080)$ & $(0.084)$ & $(0.115)$ \\
Free market price of pork & 0.019 & $0.0664 * * *$ & $0.072 * * *$ & -0.022 & $0.049 * * *$ & 0.030 \\
& $(0.020)$ & $(0.0192)$ & $(0.026)$ & $(0.021)$ & $(0.013)$ & $(0.020)$ \\
Free market price of regular rice & -0.010 & 0.0190 & $0.061 *$ & -0.001 & $-0.049 *$ & $-0.044 *$ \\
& $(0.034)$ & $(0.0225)$ & $(0.033)$ & $(0.026)$ & $(0.027)$ & $(0.026)$ \\
Free market price of flour & -0.009 & -0.0143 & -0.019 & $0.032 *$ & $0.030 *$ & 0.023 \\
& $(0.019)$ & $(0.0196)$ & $(0.021)$ & $(0.019)$ & $(0.016)$ & $(0.015)$ \\
Village has a clinic & -0.025 & -0.120 & -0.223 & -0.175 & -0.071 & -0.013 \\
& $(0.145)$ & $(0.139)$ & $(0.160)$ & $(0.179)$ & $(0.113)$ & $(0.167)$ \\
(\%) Other households with tap water & $0.322 * *$ & $0.329 * *$ & 0.107 & -0.026 & 0.034 & -0.128 \\
& $(0.160)$ & $(0.151)$ & $(0.182)$ & $(0.194)$ & $(0.160)$ & $(0.208)$ \\
\hline Province specific year dummies & Yes & Yes & Yes & Yes & Yes & Yes \\
Number of observations & 935 & 991 & 933 & 491 & 511 & 455 \\
\hline
\end{tabular}

Notes: Standard errors in parenthesis are robust to heteroskedasticity and permit within village correlations in unobservables. $* * *$ significant at $1 \%$; ** significant at $5 \%$; significant at $10 \%$. 
Table 3. Instrumental variables estimations on height-for-age, weight-for-age, and BMI-for-age z-scores, China Health and Nutrition Survey, 1997-2006

\begin{tabular}{|c|c|c|c|c|c|c|}
\hline \multirow{4}{*}{$\Delta$ Parent(s) migrated } & \multicolumn{2}{|c|}{ HAZ } & \multicolumn{2}{|c|}{ WAZ } & \multicolumn{2}{|c|}{ BMIZ } \\
\hline & $\begin{array}{c}\text { First } \\
\text { Stage }\end{array}$ & $\begin{array}{c}\text { Second } \\
\text { Stage }\end{array}$ & $\begin{array}{c}\text { First } \\
\text { Stage }\end{array}$ & $\begin{array}{c}\text { Second } \\
\text { Stage }\end{array}$ & $\begin{array}{l}\text { First } \\
\text { Stage }\end{array}$ & $\begin{array}{c}\text { Second } \\
\text { Stage }\end{array}$ \\
\hline & & 0.058 & & $0.190 * *$ & & 0.105 \\
\hline & & $(0.736)$ & & $(0.092)$ & & $(0.074)$ \\
\hline Individual Characteristics & yes & yes & yes & yes & yes & yes \\
\hline Household Characteristics & yes & yes & yes & yes & yes & yes \\
\hline Village Characteristics and Food Prices & yes & yes & yes & yes & yes & yes \\
\hline Province specific year dummies & yes & yes & yes & yes & yes & yes \\
\hline \multicolumn{7}{|l|}{ Instrument Variables } \\
\hline Growth of male daily wage in provincial & \multirow{2}{*}{\multicolumn{2}{|c|}{$\begin{array}{c}0.105^{* * *} * \\
(0.046)\end{array}$}} & \multirow{2}{*}{\multicolumn{2}{|c|}{$\begin{array}{l}0.081 * \\
(0.041)\end{array}$}} & \multicolumn{2}{|c|}{$0.119 * * *$} \\
\hline capital city $\times$ initial village male migration rate & & & & & $(0$ & 45) \\
\hline Growth of female daily wage in provincial & \multicolumn{2}{|c|}{$0.126^{* * *}$} & \multicolumn{2}{|c|}{$0.118 * * *$} & \multicolumn{2}{|c|}{$0.118 * * *$} \\
\hline capital city $\times$ initial village female migration rate & \multicolumn{2}{|c|}{$(0.052)$} & \multicolumn{2}{|c|}{$(0.048)$} & \multicolumn{2}{|c|}{$(0.053)$} \\
\hline F test on excluded instruments & \multicolumn{2}{|c|}{7.795} & \multicolumn{2}{|c|}{6.243} & \multicolumn{2}{|c|}{7.682} \\
\hline Prob $>$ F & \multicolumn{2}{|c|}{0.0007} & \multicolumn{2}{|c|}{0.003} & \multicolumn{2}{|c|}{0.0007} \\
\hline Over identification: Hansen J statistic & \multicolumn{2}{|c|}{0.226} & \multicolumn{2}{|c|}{0.034} & \multicolumn{2}{|c|}{1.305} \\
\hline Chi-sq(1) p-val & \multicolumn{2}{|c|}{0.634} & \multicolumn{2}{|c|}{0.854} & \multicolumn{2}{|c|}{0.253} \\
\hline Confidence intervals derived from weak-instrument robust tests & \multicolumn{2}{|c|}{$[-2.596,1.312]$} & \multicolumn{2}{|c|}{$[0.055,0.550]$} & \multicolumn{2}{|c|}{$[-0.0153,0.320]$} \\
\hline Number of observations & \multicolumn{2}{|c|}{491} & \multicolumn{2}{|c|}{511} & \multicolumn{2}{|c|}{455} \\
\hline
\end{tabular}

Notes: Standard errors in parenthesis are robust to heteroskedasticity and permit within village correlations in unobservables. $* * *$ significant at $1 \%$; * significant at $5 \%$; significant at $10 \%$. 
Table 4. Robustness check: instrumental variables estimations without household characteristics, China Health and Nutrition Survey, 1997-2006

\begin{tabular}{|c|c|c|c|}
\hline \multirow{3}{*}{$\Delta$ Parent(s) migrated } & $\Delta \mathbf{H A Z}$ & $\Delta \mathbf{W A Z}$ & $\Delta$ BMIZ \\
\hline & 0.034 & $0.077^{*}$ & 0.030 \\
\hline & $(0.425)$ & $(0.042)$ & $(0.041)$ \\
\hline Individual Characteristics & yes & yes & yes \\
\hline Household Characteristics & no & no & no \\
\hline Village Characteristics and Food Prices & yes & yes & yes \\
\hline Province specific year dummies & yes & yes & yes \\
\hline F test on excluded instruments & 11.00 & 8.59 & 11.33 \\
\hline Prob $>F$ & 0.000 & 0.001 & 0.000 \\
\hline Over identification: Hansen J statistic & 0.149 & 0.301 & 1.393 \\
\hline Chi-sq(1) p-val & 0.700 & 0.583 & 0.238 \\
\hline Confidence intervals derived from weak-instrument robust tests & {$[-1.566,0.860]$} & {$[0.008,0.241]$} & {$[-0.042,0.189]$} \\
\hline Number of observations & 491 & 511 & 455 \\
\hline
\end{tabular}

Notes: Standard errors in parenthesis are robust to heteroskedasticity and permit within village correlations in unobservables. *** significant at $1 \%$; ** significant at 5\%; * significant at $10 \%$. 
Table 5: Anthropometric measures and parent migration status by panel attrition, China Health and Nutrition Survey, 1997-2006

\begin{tabular}{|c|c|c|c|}
\hline & \multicolumn{3}{|c|}{ Mean Difference by Attrition } \\
\hline & Stayers & Leavers & $(1)-(2)$ \\
\hline & (1) & $(2)$ & (3) \\
\hline \multicolumn{4}{|l|}{ 1997-2000 Panel } \\
\hline Height-for-age z-score & -1.159 & -0.937 & -1.445 \\
\hline Weight-for-age z-score & -0.524 & -0.253 & -1.812 \\
\hline BMI-for-age z-score & 0.371 & 0.535 & -1.037 \\
\hline Parent(s) migrated & 0.064 & 0.073 & -0.315 \\
\hline Number of children & 219 & 116 & \\
\hline \multicolumn{4}{|l|}{ 2000-2004 Panel } \\
\hline Height-for-age z-score & -1.218 & -1.163 & -0.321 \\
\hline Weight-for-age z-score & -0.452 & -0.308 & -0.907 \\
\hline BMI-for-age z-score & 0.359 & 0.304 & 0.323 \\
\hline Parent(s) migrated & 0.132 & 0.177 & -1.094 \\
\hline Number of children & 219 & 133 & \\
\hline \multicolumn{4}{|l|}{ 2004-2006 Panel } \\
\hline Height-for-age z-score & -1.152 & -0.993 & -0.678 \\
\hline Weight-for-age z-score & -0.214 & -0.096 & -0.586 \\
\hline BMI-for-age z-score & 0.359 & 0.601 & -1.189 \\
\hline Parent(s) migrated & 0.233 & 0.259 & -0.454 \\
\hline Number of children & 73 & 220 & \\
\hline
\end{tabular}

Note: Sample means are reported in column (1) and (2). The last column reports t-statistics for testing the equality of the two sample means. 
Table 6. Robustness check: instrumental variables estimations with inverse probability weighting to correct for panel attrition, China Health and Nutrition Survey, 1997-2006

\begin{tabular}{|c|c|c|c|}
\hline & 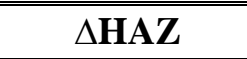 & $\triangle \mathbf{W A Z}$ & $\Delta$ BMIZ \\
\hline$\Delta$ Parent(s) migrated & $\begin{array}{l}-0.175 \\
(0.735)\end{array}$ & $\begin{array}{l}0.203^{*} \\
(0.111)\end{array}$ & $\begin{array}{c}0.101 \\
(0.074)\end{array}$ \\
\hline Individual Characteristics & yes & yes & yes \\
\hline Household Characteristics & yes & yes & yes \\
\hline Village Characteristics and Food Prices & yes & yes & yes \\
\hline Province specific year dummies & yes & yes & yes \\
\hline F test on excluded instruments & 5.69 & 5.31 & 7.82 \\
\hline Prob $>\mathrm{F}$ & 0.004 & 0.006 & 0.001 \\
\hline Over identification: Hansen J statistic & 0.125 & 0.188 & 1.872 \\
\hline Chi-sq(1) p-val & 0.724 & 0.665 & 0.171 \\
\hline Confidence intervals derived from weak-instrument robust tests & {$[-2.649,1.135]$} & {$[0.032,0.697]$} & {$[-0.019,0.302]$} \\
\hline Number of observations & 491 & 511 & 455 \\
\hline
\end{tabular}

Notes: Standard errors in parenthesis are robust to heteroskedasticity and permit within village correlations in unobservables. *** significant at $1 \%$; ** significant at $5 \%$; * significant at $10 \%$. 
Table 7. Instrumental variables estimates of impacts of migration on hygiene environment and health inputs: China Health and Nutrition Survey, 1997-2006

\begin{tabular}{|c|c|c|c|c|}
\hline \multirow{3}{*}{$\Delta$ Parent(s) Migrated } & $\begin{array}{c}\Delta \text { In-house flush } \\
\text { toilet }\end{array}$ & $\begin{array}{c}\text { In-house or } \\
\text { in-yard tap } \\
\text { water } \\
\end{array}$ & $\begin{array}{c}\Delta \text { Immunization } \\
\text { last year }\end{array}$ & $\begin{array}{c}\text { Physical } \\
\text { check-up past } \\
4 \text { weeks }\end{array}$ \\
\hline & 0.456 & $0.073 * * *$ & -0.109 & -0.148 \\
\hline & $(0.349)$ & $(0.031)$ & $(0.321)$ & $(0.120)$ \\
\hline Individual Characteristics & yes & yes & yes & yes \\
\hline Household Characteristics & yes & yes & yes & yes \\
\hline Village Characteristics and Food Prices & yes & yes & yes & yes \\
\hline Province specific year dummies & yes & yes & yes & yes \\
\hline F test on excluded instruments & 5.52 & 5.53 & 7.88 & 8.11 \\
\hline Prob $>$ F & 0.005 & 0.005 & 0.001 & 0.001 \\
\hline Over identification: Hansen J statistic & 0.672 & 0.024 & 0.099 & 0.000 \\
\hline Chi-sq(1) p-val & 0.413 & 0.878 & 0.753 & 0.986 \\
\hline $\begin{array}{l}\text { Confidence intervals derived from weak-instrument } \\
\text { robust tests }\end{array}$ & {$[-0.148,1.525]$} & {$[-0.001,0.121]$} & {$[-0.910,0.539]$} & {$[-0.390,0.075]$} \\
\hline Number of observations & 405 & 444 & 459 & 476 \\
\hline
\end{tabular}




\section{Appendix Table 1. Summary Statistics}

\begin{tabular}{|c|c|c|c|c|c|}
\hline & All & 1997 & 2000 & 2004 & 2006 \\
\hline \multicolumn{6}{|l|}{ Children Characteristics } \\
\hline \multirow[t]{2}{*}{ Age } & 4.62 & 2.75 & 4.42 & 6.14 & 5.27 \\
\hline & $(2.38)$ & $(1.57)$ & (2.13) & $(2.29)$ & $(1.81)$ \\
\hline \multirow[t]{2}{*}{ Boy } & 0.62 & 0.67 & 0.64 & 0.59 & 0.54 \\
\hline & $(0.49)$ & $(0.47)$ & $(0.48)$ & $(0.49)$ & $(0.50)$ \\
\hline \multicolumn{6}{|l|}{ Nutrition Outcomes and Inputs } \\
\hline \multirow{2}{*}{ Height-for-age z-score } & -1.06 & -1.12 & -1.17 & -0.86 & -0.92 \\
\hline & $(1.40)$ & $(1.30)$ & $(1.35)$ & $(1.50)$ & $(1.44)$ \\
\hline \multirow[t]{2}{*}{ Weight-for-age z-score } & -0.46 & -0.45 & -0.54 & -0.44 & -0.11 \\
\hline & $(1.35)$ & $(1.24)$ & $(1.30)$ & $(1.42)$ & (1.63) \\
\hline \multirow[t]{2}{*}{ BMI-for-age z-score } & 0.18 & 0.41 & 0.17 & 0.02 & 0.24 \\
\hline & $(1.41)$ & (1.36) & (1.37) & $(1.43)$ & (1.66) \\
\hline \multirow[t]{2}{*}{ Calorie intake (kcal per day) } & 1240.49 & 1025.55 & 1272.56 & 1380.26 & 1075.3 \\
\hline & $(561.91)$ & $(431.43)$ & $(568.68)$ & $(605.73)$ & $(439.80)$ \\
\hline \multirow{2}{*}{ In-house flush toilet } & 0.18 & 0.14 & 0.14 & 0.21 & 0.28 \\
\hline & $(0.38)$ & $(0.35)$ & $(0.35)$ & $(0.41)$ & $(0.45)$ \\
\hline \multirow[t]{2}{*}{ No excreta around house } & 0.55 & 0.48 & 0.54 & 0.59 & 0.66 \\
\hline & $(0.50)$ & $(0.50)$ & $(0.50)$ & $(0.49)$ & $(0.48)$ \\
\hline \multirow[t]{2}{*}{ In-house or in-yard tap water } & 0.53 & 0.43 & 0.49 & 0.64 & 0.71 \\
\hline & $(0.50)$ & $(0.50)$ & $(0.50)$ & $(0.48)$ & $(0.46)$ \\
\hline \multirow[t]{2}{*}{ Immunization last year } & 0.87 & 0.93 & 0.95 & 0.79 & 0.73 \\
\hline & $(0.33)$ & $(0.26)$ & $(0.22)$ & $(0.41)$ & $(0.45)$ \\
\hline \multirow{2}{*}{ Physical check-up past 4 weeks } & 0.03 & 0.04 & 0.03 & 0.03 & 0.02 \\
\hline & $(0.17)$ & $(0.19)$ & $(0.17)$ & $(0.18)$ & $(0.15)$ \\
\hline \multicolumn{6}{|l|}{ Household Characteristics } \\
\hline \multirow[t]{2}{*}{ Head's years of schooling } & 6.78 & 6.7 & 7.02 & 6.66 & 6.11 \\
\hline & (3.39) & $(3.52)$ & $(3.28)$ & $(3.32)$ & $(3.79)$ \\
\hline \multirow[t]{2}{*}{ No. of female aged 60 and above } & 0.16 & 0.14 & 0.15 & 0.19 & 0.2 \\
\hline & $(0.37)$ & $(0.35)$ & $(0.35)$ & $(0.40)$ & $(0.40)$ \\
\hline \multirow[t]{2}{*}{ No. of male aged 60 and above } & 0.12 & 0.08 & 0.1 & 0.17 & 0.18 \\
\hline & $(0.33)$ & $(0.26)$ & $(0.30)$ & $(0.37)$ & $(0.38)$ \\
\hline \multirow[t]{2}{*}{ No. of working-age men } & 1.09 & 1.15 & 1.14 & 1.01 & 0.93 \\
\hline & $(0.56)$ & $(0.48)$ & $(0.55)$ & $(0.59)$ & $(0.63)$ \\
\hline \multirow[t]{2}{*}{ No. of working-age women } & 1.2 & 1.27 & 1.23 & 1.14 & 1.09 \\
\hline & $(0.56)$ & $(0.61)$ & $(0.52)$ & $(0.55)$ & $(0.59)$ \\
\hline \multirow[t]{2}{*}{ Assets per capita $(\log )$} & 6.81 & 6.89 & 6.77 & 6.86 & 6.69 \\
\hline & (1.49) & (1.47) & $(1.47)$ & $(1.51)$ & $(1.58)$ \\
\hline \multicolumn{6}{|c|}{ Village Characteristics and Food Price } \\
\hline Average income per capita & 2483.88 & 1761.24 & 2273.53 & 2543.20 & 3265.70 \\
\hline & (1487.53) & $(861.44)$ & $(1252.07)$ & (1198.82) & (1953.08) \\
\hline Free market price of pork & 10.13 & 11.35 & 9.15 & 11.29 & 7.78 \\
\hline & $(3.15)$ & $(3.21)$ & $(3.20)$ & $(2.28)$ & $(2.31)$ \\
\hline Free market price of regular rice & 1.92 & 2.33 & 1.65 & 2.04 & 1.83 \\
\hline & (1.73) & $(2.86)$ & $(0.99)$ & (1.64) & $(0.54)$ \\
\hline Free market price of flour & 2.05 & 2.16 & 1.79 & 2.45 & 1.63 \\
\hline & (1.92) & $(1.65)$ & $(0.60)$ & (3.16) & $(0.35)$ \\
\hline Village has a clinic & 0.79 & 0.8 & 0.8 & 0.77 & 0.81 \\
\hline & $(0.41)$ & $(0.40)$ & $(0.40)$ & $(0.42)$ & $(0.39)$ \\
\hline (\%) Other households with tap & 0.54 & 0.45 & 0.51 & 0.62 & 0.7 \\
\hline water & $(0.41)$ & $(0.43)$ & $(0.40)$ & $(0.41)$ & $(0.39)$ \\
\hline
\end{tabular}

Notes: Standard deviations are in parentheses. Samples include children who were 0-5 in 1997, 2000, 2004 and were surveyed for two consecutive rounds. 


\section{Appendix Table 2. Estimation of attrition probabilities}

\begin{tabular}{|c|c|c|c|}
\hline & \multicolumn{3}{|c|}{ Dependent variable: stay=1; move $=0$} \\
\hline & $(2000 \mid 1997)$ & $(2004 \mid 2000)$ & $(2006 \mid 2004)$ \\
\hline \multirow[t]{2}{*}{ Height-for-age z-score } & -0.000 & -0.016 & -0.000 \\
\hline & $(0.016)$ & $(0.011)$ & $(0.007)$ \\
\hline \multirow[t]{2}{*}{ Parent(s) Migrated } & 0.002 & -0.105 & -0.049 \\
\hline & $(0.128)$ & $(0.098)$ & $(0.054)$ \\
\hline \multirow[t]{2}{*}{ Child age } & 0.074 & 0.023 & -0.014 \\
\hline & $(0.065)$ & $(0.063)$ & $(0.042)$ \\
\hline \multirow[t]{2}{*}{ Boy } & $0.056 * * *$ & $0.042 * *$ & $0.072 * * *$ \\
\hline & $(0.020)$ & $(0.020)$ & $(0.015)$ \\
\hline \multirow[t]{2}{*}{ Head's years of schooling } & 0.007 & -0.010 & -0.003 \\
\hline & $(0.010)$ & $(0.010)$ & $(0.007)$ \\
\hline \multirow[t]{2}{*}{ No. of female aged 60 and above } & $0.159 *$ & -0.001 & 0.066 \\
\hline & $(0.082)$ & $(0.120)$ & $(0.074)$ \\
\hline \multirow[t]{2}{*}{ No. of male aged 60 and above } & -0.189 & -0.115 & -0.074 \\
\hline & $(0.125)$ & $(0.115)$ & $(0.053)$ \\
\hline \multirow[t]{2}{*}{ No. of working-age men } & -0.050 & $-0.174 * * *$ & -0.057 \\
\hline & $(0.062)$ & $(0.060)$ & $(0.040)$ \\
\hline \multirow[t]{2}{*}{ No. of working-age women } & 0.031 & 0.069 & 0.009 \\
\hline & $(0.061)$ & $(0.071)$ & $(0.031)$ \\
\hline \multirow[t]{2}{*}{ Household assets per capita (log) } & 0.026 & $-0.049 * *$ & -0.007 \\
\hline & $(0.024)$ & $(0.025)$ & $(0.017)$ \\
\hline \multirow[t]{2}{*}{ Average income per capita in the village } & -0.098 & -0.117 & $-0.090 * * *$ \\
\hline & $(0.100)$ & $(0.077)$ & $(0.023)$ \\
\hline \multirow[t]{2}{*}{ Free market price of pork } & -0.015 & -0.021 & $0.015^{* *}$ \\
\hline & $(0.010)$ & $(0.020)$ & $(0.006)$ \\
\hline \multirow[t]{2}{*}{ Free market price of regular rice } & -0.003 & -0.000 & -0.004 \\
\hline & $(0.013)$ & $(0.069)$ & $(0.003)$ \\
\hline \multirow[t]{2}{*}{ Free market price of flour } & 0.014 & -0.000 & $0.053 * * *$ \\
\hline & $(0.012)$ & $(0.013)$ & $(0.017)$ \\
\hline \multirow[t]{2}{*}{ Village has a clinic } & 0.003 & -0.031 & $-0.257 * * *$ \\
\hline & $(0.108)$ & $(0.082)$ & $(0.083)$ \\
\hline \multirow[t]{2}{*}{ (\%) Other households with tap water } & $-0.176^{*}$ & -0.008 & 0.010 \\
\hline & $(0.103)$ & $(0.108)$ & $(0.073)$ \\
\hline \multirow[t]{2}{*}{ Heilongjiang Province } & $0.177 * *$ & 0.154 & $0.386 * *$ \\
\hline & $(0.085)$ & $(0.118)$ & $(0.174)$ \\
\hline \multirow[t]{2}{*}{ Jiangsu Province } & -0.083 & 0.159 & $-0.090 *$ \\
\hline & $(0.160)$ & $(0.131)$ & $(0.053)$ \\
\hline \multirow[t]{2}{*}{ Shandong Province } & -0.189 & -0.060 & 0.038 \\
\hline & $(0.182)$ & $(0.183)$ & $(0.130)$ \\
\hline \multirow[t]{2}{*}{ Henan Province } & $-0.293 * *$ & 0.120 & -0.093 \\
\hline & $(0.137)$ & $(0.115)$ & $(0.061)$ \\
\hline Hubei Province & -0.111 & -0.125 & 0.111 \\
\hline & $(0.124)$ & $(0.126)$ & $(0.132)$ \\
\hline Hunan Province & -0.023 & -0.123 & 0.097 \\
\hline & $(0.176)$ & $(0.108)$ & $(0.135)$ \\
\hline Guangxi Zhuang Autonomous Region & 0.028 & 0.080 & $-0.131 * * *$ \\
\hline & $(0.110)$ & $(0.114)$ & $(0.039)$ \\
\hline Liaoning Province & & 0.144 & $-0.142 * * *$ \\
\hline & & $(0.105)$ & $(0.039)$ \\
\hline Number of observations & 335 & 352 & 293 \\
\hline
\end{tabular}

Notes: Marginal effects from probit model estimations are reported. Standard errors in parenthesis are robust to heteroskedasticity and permit within village correlations in unobservables. $* * *$ significant at $1 \%$; ** significant at $5 \%$; significant at $10 \%$. 


\section{REFERENCES}

Alderman H, Jerry Behrman, Victor Lavy, and Rikha Menon. Child Health and School Enrollment. Journal of Human Resources 2001;36; 185-205.

Azzarri C, and Alberto Zezza. International Migration and Nutritional Outcomes in Tajikistan. Food Policy 2011;36; 54-70.

Beine M, Frederic Docquier, and Hillel Rapoport. Brain Drain and Human Capital Formation in Developing Countries: Winners and Losers. The Economic Journal 2008;118; 631-652.

Bouis H. The Effect of Income on Demand for Food in Poor Countries: Are Our Databases Giving us Reliable Estimates? Journal of Development Economics 1994;44; 199-226.

Cai F, Albert Park, and Yaohui Zhao. 2008. The Chinese Labor Market in the Reform Era. In: Brandt, L, and Tom Rawski (Eds), China's Economic Transition: Origins, Mechanisms, and Consequences. Cambridge University Press: Cambridge; 2008.

Carba, D., V.L. Tan, and L.S. Adair. Early Childhood Length-fir-Age is Associate with the Work status of Filipino Young Adults. Economics and Human Biology 2009; 7; 7-17.

Carletto C, Katia Covarrubias, and John A. Maluccio. Migration and Child Growth in Rural Guatemala. Food Policy 2011;36; 16-27.

Chen C. Fat intake and Nutritional Status of Childre in China. American Journal of Clinical Nutrition 2000;72; 1368S-1372S.

Chen JJ. Migration and Imperfect Monitoring: Implications for Intra-household Allocation. American Economic Review 2006;96; 227-231.

Chen X, Qiuqiong Huang, Scott Rozelle, Yaojiang Shi, and Linxiu Zhang. Effect of Migration on Children's Educational Performance in Rural China. Comparative Economic Studies 2009;51;323-343.

Clemens MA. Economics and Emigration: Trillion-Dollar Bills on the Sidewalk? Journal of Economic Perspectives 2011;25; 83-106.

Davin D. Internal Migration in Contemporary Chinas. St. Martin's Press: New York, NY; 1999.

de Brauw A. Migration and Child Development during the Food Price Crisis in El Salvador. Food Policy 2011;36(1);28-40.

de Brauw A, and J. Giles. Migrant Labor and the Welfare of Rural Households in the Developing World: Evidence from China. World Bank Policy Research Working 
Paper 4585,2008.

de Brauw A, Quang Li, Chengfang Liu, Scott Rozelle, and Linxiu Zhang. Is Feminization of Agriculture Ocurring in China? Debunking the Myth and Measuring the Consequence of Women's Participation in Agriculture. China Quarterly 2008;194; 327-348.

de Brauw A, and Ren Mu. Migration and the Overweight and Underweight Status of Children in Rural China. Food Policy 2011; 88-100.

de Onis M, A.W. Onyango, E. Borghi, A. Siyam, C. Nishida, and J. Siekmann. Development of a WHO Reference for School-aged Children and Adolescents. Bulletin of the World Health Organization 2007;85; 660-667.

Du S, T.A. Mroz, F. Zhai, and B.M. Popkin. Rapid Income Growth Adversely Affects Diet Quality in China - Particularly for the Poor! Social Science and Medicine 2004;59; 1505-1515.

Du Y, Albert Park, and Sangui Wang. Migration and Rural Poverty in China. Journal of Comparative Economics 2005;33; 688-709.

Duflo E. Grandmothers and Granddaughters: Old-Age Pensions and Intrahousehold Allocation in South Africa. World Bank Economic Review 2003;17; 1-25.

Fan CC. China on the Move : Migration, the State, and the Households. Routledge: London ; New York; 2008.

Fei JCH, Ranis G. Development of the Labor Surplus Economy : Theory and Policys. R. D. Irwin: Homewood, Ill.; 1964.

Finlay K, and Leandro M. Magnusson. Implementing Weak Instrument Robust Tests for a General Class of Instrumental Variables Models. Stata Journal 2009;9; 398-421.

Gibson J, David Mckenzie, and Steven Stillman. What happens to diet and child health when migration splits households? Evidence from a migration lottery program. Food Policy 2011;36; 7-15.

Giles J. Is Life More Risky in the Open? Household Risk-Coping and the opening of China's Labor Markets. Journal of Development Economics 2006;81; 25-60.

Giles J, Dewen Wang, and Changbao Zhao. Can China's rural elderly count on support from adult children? Implications of rural-to-urban migration. World Bank, Policy Research Working Paper 2011.

Giles J, and Kyeongwon Yoo. Precautionary Behavior, Migrant Networks and Household Consumption Decisions: An Empirical Analysis Using Household Panel Data from Rural China. The Review of Economics and Statistics 2007; 89(3); 534-551. 
Glewwe P, and Edward Miguel. The Impact of Child Health and Nutrition on Education in Less Developed Countries. In: Shultz, TP and John Strauss (Eds.), Handbook of Development Economics vol. 4. North Holland: Amsterdam; 2008.

Glewwe P, and Hanan Jacoby. An Economic Analysis of delayed primary enrollment in a low income country: the role of early childhood nutrition. Review of Economic Statistics 1995;77; 156-169.

Grantham-McGregor, S., Y.B. Cheung, S. Cueto, P. Glewwe, L. Richter, B. Strupp, and the International Child Development Steering Group. Developmental Potential in the first 5 years for children in developing countries. The Lancet 2007; 369; 60-70.

Guo L. 2009. Living Arrangements of Migrants' Left-behind Children in China. Paper Presented at the Population Association of America. 2009.

Lewis WA. Economic Development with Unlimited Supplies of Labor. Manchester School 1954;28; 139-191.

Liang Z, and Zhongdong Ma. China's Floating Population: New Evidence from the 2000 Census. Population and Development Review 2004;30; 467-488.

Luo R, Yaojiang Shi, Linxiu Zhang, Chengfang Liu, Scott Rozelle, Brian Sharbono, Ai Yue, Qiran Zhao, Reynaldo Martorell. Nutrition and Educational Performance in Rural China's Elementary Schools: Results of a Randomized Control Trial in Shaanxi Province. Economic Development and Cultural Change forthcoming.

Mallee H. China's Household Registration System under Reform. Development and Change 1995;26; 1-29.

Maluccio J, John Hoddinott, Jere R. Behrman, Reynaldo Martorell, Agnes R. Quisumbing, and Aryeh D. Stein. The Impact of Improving Nutrition During Early Childhood on Education among Guatemalan Adults. The Economic Journal 2009; 119; 734-763.

Mangyo E. The Effect of Water Accessibility on Child Health in China. Journal of Health Economics 2008;27; 1343-1356.

Mansuri G. Migration, Sex Bias, and Child Growth in Rural Pakistan. World Bank Policy Research Working Paper Series 39462006.

Miguel E, and Michel Kremer. Worms: Identifying impacts on education and health in the presence of treatment externalities. Econometrica 2004;72; 159-217.

Monda KL, Popkin BM. Cluster Analysis Methods Help to Clarify the Activity-BMI Relationship of Chinese youth. Obesity research 2005;13; 1042-1051.

Moreira, M. A Conditional Likelihood Ratio Test for Structural Models. Econometrica 2003; 71(4); 1027-1048. 
Mu R, and Dominique van de Walle. Left Behind to Farm? Women's Labor Reallocation in Rural China. Labor Economics 2011;18: S83-S97.

Munshi K. Networks in the Modern Economy: Mexican Migrants in the US Labor Market. Quarterly Journal of Economics 2003;118; 549-597.

Nguyen MC, and Paul Winters. The Impact of Migration on Food Consumption Patterns: The Case of Vietnam. Food Policy 2011;36; 71-87.

Nobles J. Parental Migration and Child Health in Mexico. Working paper, University of California: Los Angeles; 2007.

Osberg L, Jiaping Shao and Kuan Xu. The Growth of Poor Children in China 1991-2000: Why Food Subsidies May Matter. Health Economics 2009;18; S89-S108.

Özaltin E, Hill K, Subramanian S V. Association of Maternal Stature with Offspring Mortality, Underweight, and Stunting in Low-to-Middle Income Countries. JAMA 2010, 303, 15: 1507-1516.

Parrenas RS. Children of Global Migration: Transnational Families and Gendered Woess. Stanford University Press: Palo Alto; 2005.

Rozelle S, L. Guo, M. Shen, A. Hughart, J. Giles. Leaving China's Farms: Survey Results of New Paths and Remaining Hurdles to Rural Migration. China Quarterly $1999 ; 158 ; 367-393$.

Schroeder, D.G., R. Martorell, J.A. Rivera, M.T. Ruel, and J.P. Habicht. Age Differences in the Impact of Nutritional Supplement on Growth. Journal of Nutrition 1995; $125 ; 1051$ S-1059S.

Shen T, Jean-Pierre Habicht, and Ying Chang. Effect of Economic Reforms on Child Growth in Urban and Rural Areas of China. The New England Journal of Medicine 1996;335; 400-406.

Stark O, and David Bloom. The New Economics of Labor Migration. American Economic Review 1985;75; 173-178.

Stock J, and Motohiro Yogo. 2005. Testing for Weak Instruments in Linear IV Regression. In: Andrews DWK (Ed), Identifications and Inference for Econometric Models. Cambridge University Press: New York; 2005.

Subramanian S, and Angus Deaton. The Demand for Food and Calories. Journal of Poltical Economy 1996;104; 133-162.

Svedberg P. Declining Child Malnutrition: a Reassessment. International Journal of Epidemiology 2006;35; 1336-1346.

Thomas D. Intra-Household Resource Allocation: an Inferential Approach. Journal of 
Human Resources 1990;25; 635-664.

UNICEF. The State of Asia-Pacific's Children 2008 Child Survival. 2008.

Wagstaff A, W. Yip, M. Lindelow, and W. Hsiao. China's Health System Reform: A Review of Recent Studies. Health Economics 2009;18; S7-S23.

Walker, S.P., T.D. Wachs, S. Grantham-McGregor, M.M. Black, C.A. Nelson, S.L Huffman, H. Baker-Henningham, S.M. Chang, J.D. Hamadani, B. Lozoff, J.M. Meeks Gardner, C.A. Powell, A. Rahman, and L. Richter. Inequality in Early Childhood: Risk and Protective Factors for Early Child Development. The Lancet; 2011; 378; 1325-1338.

Woodruff C, and R. Zenteno. Migration Networks and Microenterprises in Mexico. Journal of Development Economics 2007;82; 509-528.

Wooldridge J. Econometric Analysis of Cross Section and Panel Data s. MIT Press: Cambridge, Massachusetts; 2010.

World Bank. From Poor Areas to Poor people: China's Evolving Poverty Reduction Agenda. Washington, DC; 2009.

World Health Organization. WHO Child Growth Standards: Methods and Development: Length/Height-for-Age, Weight-for-Age, Weight-for-Length, Weight-for-Height and Body Mass Index-for-Age. Geneva; 2006.

World Health Organization. Measuring Change in Nutritional Status. Geneva; 1983.

Yang D. International Migration, Remittances, and Household Investment: Evidence from Philippine Migrants' Exchange Rate Shocks. The Economic Journal 2008;118; 591-630.

Zhang J. The Impact of Water Quality on Health: Evidence from the Drinking Water Infrastructure Program in Rural China. Journal of Health Economics forthcoming.

Zhao Y. Leaving the Countryside: Rural-to-Urban Migration in China. American Economic Review 1999;89; 281-286.

Zhao Y. Causes and Consequences of Return Migration: Recent Evidence from China. Journal of Comparative Economics 2002;30; 376-394. 